\title{
Time-Frequency and Nonlinear Analysis of Tidal Data Observed on the Kuroshio Path
}

\author{
Kenta Kirimoto \\ Department of Creative Engineering, National Institute of Technology, Kitakyushu College, Fukuoka, Japan \\ Email: kirimoto@kct.ac.jp
}

How to cite this paper: Kirimoto, K. (2016) Time-Frequency and Nonlinear Analysis of Tidal Data Observed on the Kuroshio Path. International Journal of Modern Nonlinear Theory and Application, 5, 147-159. http://dx.doi.org/10.4236/ijmnta.2016.54015

Received: September 15, 2016

Accepted: November 7, 2016

Published: November 10, 2016

Copyright $\odot 2016$ by author and Scientific Research Publishing Inc. This work is licensed under the Creative Commons Attribution International License (CC BY 4.0).

http://creativecommons.org/licenses/by/4.0/

\begin{abstract}
The tidal data of Kushimoto and Uragami on flow path of Kuroshio from 2004 to 2005 are investigated and discussed by time-frequency methods and nonlinear methods in this paper. These analyzing methods based on mathematical science show us new findings about the tidal motion observed on Kuroshio flow path. On the timefrequency analysis, 12 hours component and 24 hours component swing during the period of 350 hours and 320 hours respectively. However, any remarkable differences or changes depending on Kuroshio flow path weren't seen on the result of time-frequency analysis. On the nonlinear analysis, a periodical structure has seen on the mutual information of tidal difference data, while Kuroshio flow is stable. In addition, the mutual information showed a characteristic of randomness and irregularity, while Kuroshio flow is unstable. The important results brought us a new finding such as classification of tidal motion regardless of the flow path of Kuroshio.
\end{abstract}

\section{Keywords}

Wavelet Transform, Lorenz's Plot, Mutual Information, Time Development, Periodicity, Irregularity, Classification

\section{Introduction}

Kuroshio is one of the biggest circulations of the North Pacific Ocean. Kuroshio is a large current started from Eastern Luzon Islands to Bhoso Peninsula or Sanriku coast through southern coast of the Japanese Islands. The width of Kuroshio is about $100 \mathrm{~km}$ long, and the drift speed is 2 to 4 knots. Kuroshio effects not only to the ship navigation route but also for climate of southern coast of Japan. In addition, Kuroshio flow path often changes and it is set by monitoring of surface temperature that is based on ocean buoys, satellite remote sensor and sea current data from the ocean research ship [1] [2] [3]. 
When Kuroshio greatly meanders in the Japanese southern coast, the route doesn't recover and this meandering continues about a year. This influences on the amount of fish catches and their kind. If Kuroshio flows near the coast line of Kii Peninsula, the sea level rises. Therefore, it may cause a sea disaster by its high tide. The tide level is observed at more than 150 measurement points of tide gauge stations located in all over Japan and its data are opened to the public online system. Among them, stations located at Kushimoto and Uragami in Kii Peninsula are the most important stations for monitoring Kuroshio because the flowing path of Kuroshio can be roughly estimated by analyzing the tidal data observed at Kushimoto and Uragami.

The tide level difference between Kushimoto and Uragami has been discussing about flowing path of Kuroshio by many researchers [4] [5] [6]. Tide level is originally composed of the astronomical tide and the metrological tide. The astronomical tide is a rising and falling motion of seawater which caused by the tidal force working between the sun and the earth or between the moon and the earth. The other hands, the metrological tide is a fluctuation caused by a metrological disturbance such as air presser, temperature, wind, and so on. Furthermore, tide level is risen when the Kuroshio approaching to Kii Peninsula blocked by the coast. Therefore, many researchers have payed attentions to both the astronomical tide and the metrological tide in case they discuss about the tidal data of Kuroshio. Most of the researchers have investigated the moving average of tide level to remove the influence of the astronomical and metrological tide. Maekawa et al. emphasized that the tidal difference occurs in narrow region of $4-5 \mathrm{~km}$ and is mainly created in the surface layer above $150 \mathrm{~m}$ by analyzing the tidal difference, the flow speeds of seawater, temperature, salinity [7]. Nakamura et al. discussed the seasonal variation of tidal difference by the moving average [8]. The moving average is applied to remove a noise and to observe the long-term trend from the hourly tidal data. However, this method makes lower the temporal resolution of the data and ends up losing the information in the data. To avoid this, the new methods need to be discovered which is able to analyze the tide level without using the moving average. In addition, some advanced analysis is necessary to extract the useful information from the tidal data.

In this paper, the characteristics of tidal motion are discussed by using the methods of mathematical science such as time-series analysis and nonlinear analysis. These methods without moving average bring us new findings about the tidal motion observed on Kuroshio flow path. The new finding in this paper is that the tidal motion has two different aspects in detail. The mutual information representing the characteristics of tidal motion changes the aspect between stability and irregularities. This transition process shows a cyclic loop in the classification map. The loop looks like an orbital connected at a saddle point between the side of meandering path of Kuroshio and the side of straight path.

\section{Tidal Data and Analysis Methods}

As shown in Figure 1, tidal data were taken from J-DOSS; JODC Data On-line Service 


\section{Data acquisition and data processing}

Original data, http://www.jodc.go.jp/service.htm

Tide table of Kushimoto and Uragami

26 columns 731 rows hourly data from 2004 to 2005

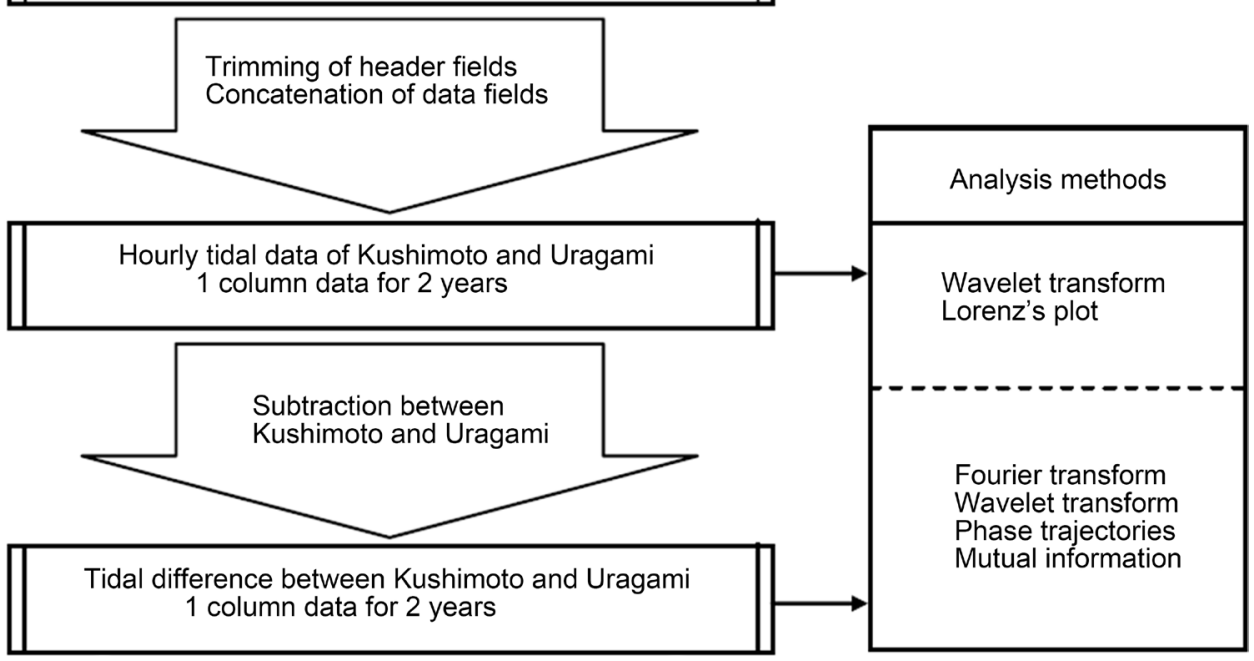

Figure 1. Outline flow chart from data acquisition to data analysis for tidal data.

System which is provided by the Japan Oceano-graphic Data Center (JODC) [9]. In this paper, tidal data observed at Kushimoto and Uragami for two years from 2004 to 2005 were intensively studied together with their tidal difference data. These data are hourly time-series data containing about 17500 points respectively. However, some data processing is necessary for analyzing of tidal data as shown in Figure 1. Hourly tidal data were analyzed by Wavelet transform and Lorenz's plot to investigate their fundamental characteristics. The difference of tide level was prepared from subtracting Uragami's data from Kushimoto's data. This tidal difference was examined precisely by using FFT, Wavelet transform, phase trajectory, and mutual information. Figure 2(a) shows typical flow paths of Kuroshio. The flow paths of Kuroshio are classified into three typical patterns. They are called large meandering path (bold line), small meandering path (break line) and straight path (dot line). Figure 2(b) shows the location of tide stations in the western parts of Japan. Above all, Kushimoto and Uragami in the southern part of Kii peninsula are the most important stations for monitoring Kuroshio. Table 1 shows the periods of Kuroshio's meandering which occurred after 1975 [5] [10]. The latest Kuroshio's meandering term was from Jun 2004 to August 2005.

\section{Results and Discussion}

\subsection{FFT Analysis and Time-Frequency Analysis}

Figure 3 shows the tidal difference between Kushimoto and Uragami from 2004 to 2005. Kuroshio moved to southward from Shiono-misaki cape at southern part of Kii peninsula and had been meandering for 13 months. Tidal difference in meandering term was relatively low and steady. On the other hand, the tidal difference while Kuroshio was hitting the Shiono-misaki showed an irregular fluctuation. Figure 4 shows the 
result of FFT analysis on the tidal difference shown in Figure 3. The major peak is observed at a frequency of 0.08 ( 1 /hour), which is the inverse number of 12 hours period. The power spectrum density on the tidal difference decreases against the increasing of frequency. The slope of spectrum is about -1 as shown Figure 4. According to the

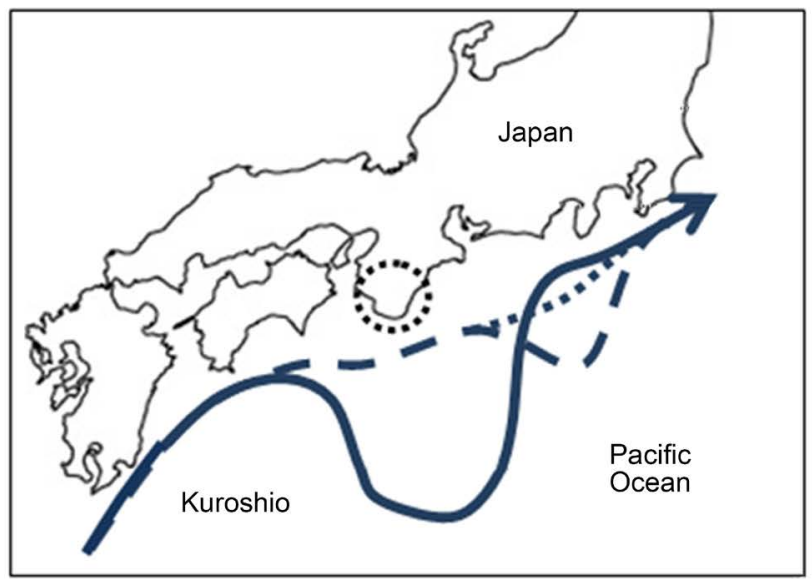

(a)

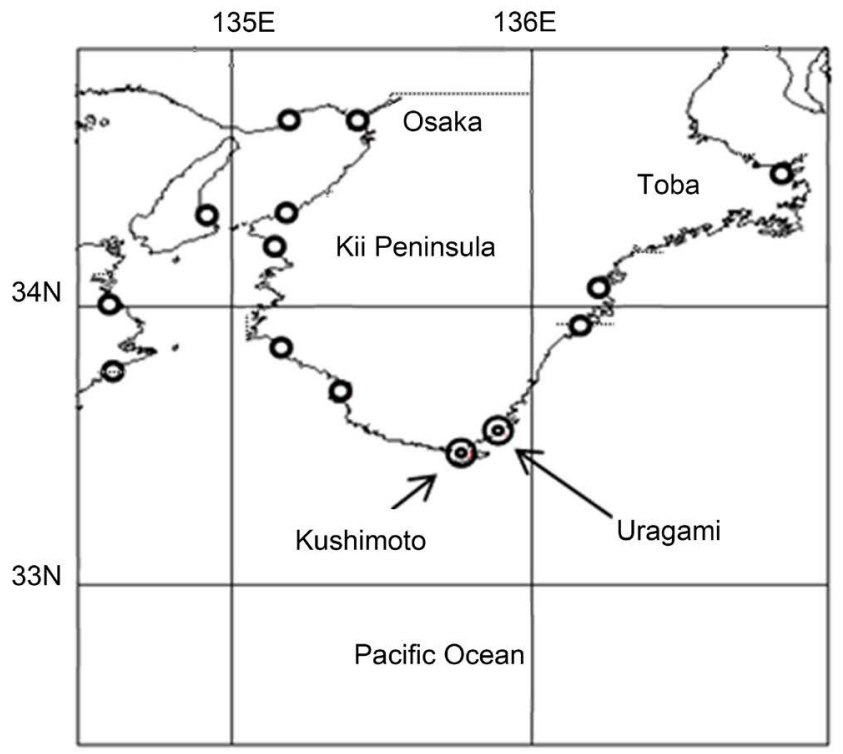

(b)

Figure 2. Tipycal flow routes of Kuroshio and location of tide stations. (a) Typical flow paths of Kuroshio; (b) Location of tide stations in the west Japan area.

Table 1. Periods on meandering Kuroshio Current after 1975.

\begin{tabular}{ccc}
\hline Beginning of meandering & Ending of meandering & Duration time \\
\hline Aug. 1975 & Mar.1980 & 4 years and 8 months \\
Nov. 1981 & May. 1984 & 2 years and 7 months \\
Dec. 1986 & Jul. 1988 & 1 year and 8 months \\
Dec. 1989 & Dec. 1990 & 1 year and 1 month \\
Jul. 2004 & Aug. 2005 & 1 year and 2 months \\
\hline
\end{tabular}



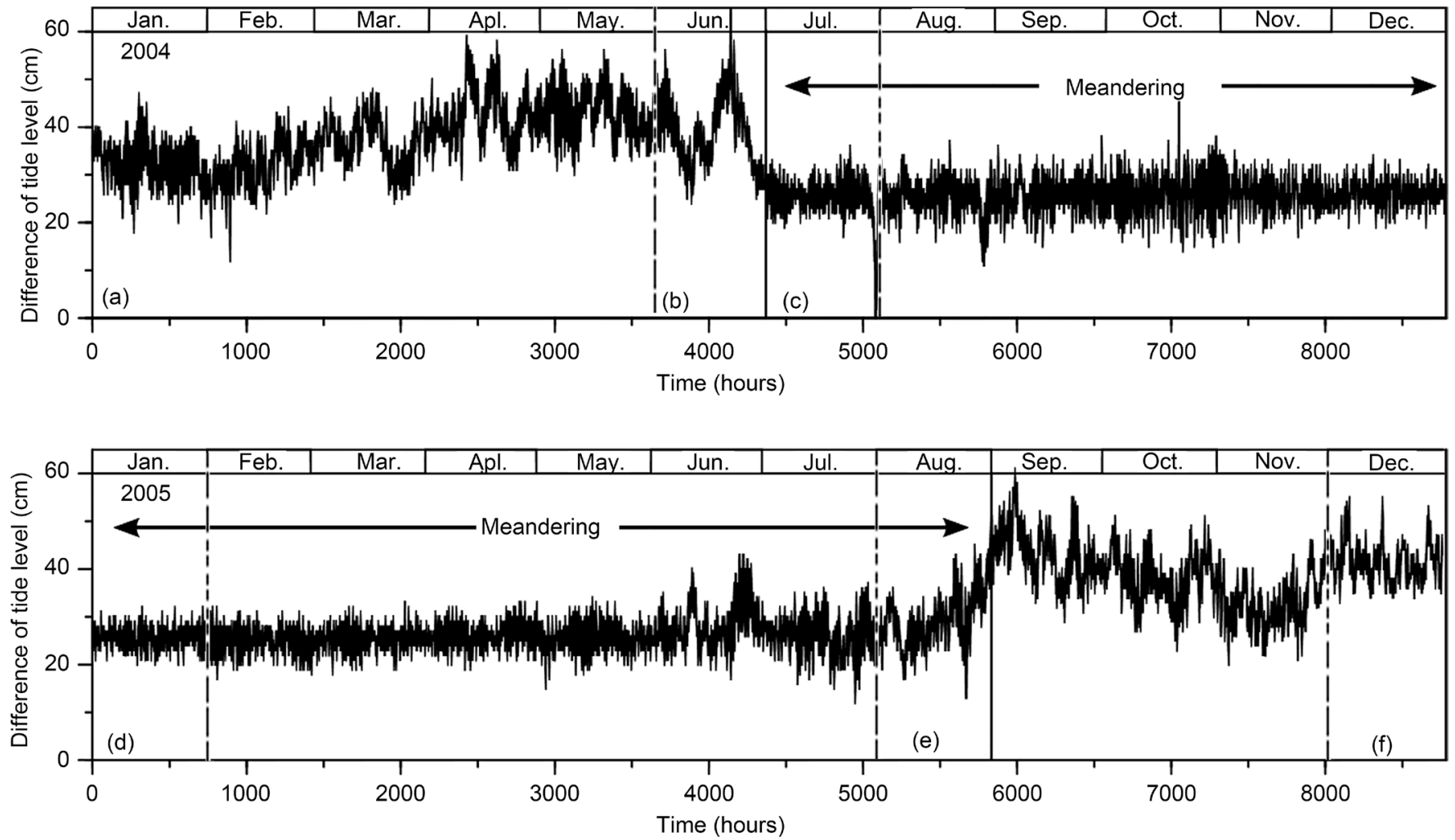

Figure 3. Tidal difference between Kushimoto and Uragami from 2004 to 2005. Kuroshio meandered from July 2004 to August 2005 . Six specific months (a) to (f) are intensively studied in this paper.

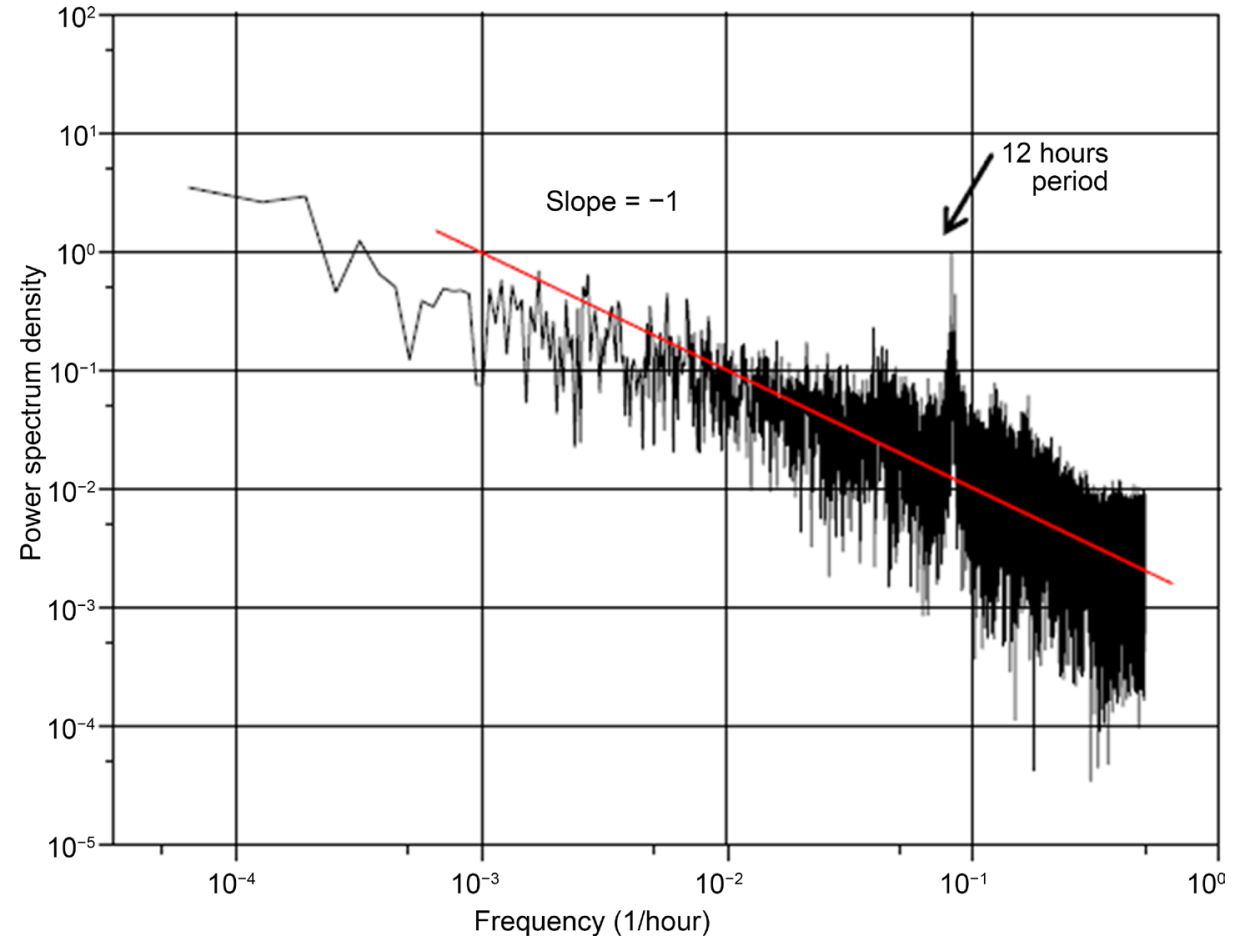

Figure 4. FFT analysis of tidal difference data between Kushimoto and Uragami. Power spectrum density of tidal difference has $1 /$ f spectrum and a small component of 12 hours. 
references [11] [12], the spectrum of tide level data shows the slope of -1 . The spectrum of tidal difference also has $1 / \mathrm{f}$ spectrum in this paper.

Figure 5 shows the wavelet analysis of the tidal data and that of tidal difference in the term Kuroshio moved from straight path to meandering path. The prominent components of semidiurnal period (12 hours) and diurnal period ( 24 hours) are indicated in Figure 5(a) and Figure 5(b). These figures are based on the wavelet analysis of Kushimoto's and Uragami's data. The powers of semidiurnal component and diurnal component have different swing periods. Semidiurnal component has a swing period of 350 hours. The diurnal component has a swing period of 320 hours. These phenomena are caused by the astronomical factor [13] [14]. Figure 5(c) shows a result of wavelet analysis of tidal difference between Kushimoto and Uragami. Two prominent components described above aren't seen in Figure 5(c). Therefore, this subtraction process needs to remove the affection of astronomical tide from the original data in this paper.

\subsection{Nonlinear Analysis}

Six specific months during 2004 to 2005 are selected to discuss the tidal motion in this paper. Figure 6 and Figure 7 show Lorenz's plots on tidal data at Kushimoto and Uragami respectively. All figures are plotted by data set of the minimum points of tide level for each 12 hours. Kuroshio flow path is described as a cyclic process that consists on some phases, (a) straight path, (b) beginning of meandering, (c) unstable meandering, (d) stable meandering, (e) ending of meandering, and (f) straight path. Lorenz's plots of Kushimoto show an arctic outline in Figure 6 (b) and Figure 6(f). On the other hand, the dispersion of Lorenz's plots can be seen in Figures 6(a)-(e). In Figure 7, though Lorenz's plots of Uragami are similar to Kushimoto in Figure 6, they are different in detail. Therefore, it is difficult to find a regularity of Lorenz's plots at this moment and these results shows a chaotic character of tidal motion.

Figure 8 shows phase trajectories of the tidal difference between Kushimoto and Uragami. Tidal difference between Kushimoto and Uragami is also important to discuss the sea level affected by Kuroshio. The time delay of phase trajectories was decided $\mathrm{t}=4$ which is the minimum point of mutual information in Figure 9(a) [15] [16]. The phase trajectory in no-meandering state forms a round shape in Figure 8(a). The trajectory is stretched in a process of changing no-meandering state into meandering state in Figure 8(b). Once Kuroshio starts meandering, the trajectories become a round again in Figure 8(c) and Figure 8(d). The stretched trajectory can be seen in the end of meandering in Figure $8(\mathrm{e})$ and Figure $8(\mathrm{f})$, in the same way as Figure $8(b)$.

Figure 9 shows mutual information of tidal difference between Kushimoto and Uragami. There are three typical features in Figure 9. First, the mutual information shows a large periodic fluctuation in Figure 9(a) and Figure 9(d). These patterns of mutual information are quite similar to the results which Friso et al. reported of a periodicity and a steadiness of tidal motion [12]. Second, in Figure 9(b) and Figure 9(e), the mu- 
tual information forms a slope and also shows a periodicity. This periodicity is longer than that of (a) and (d). Moreover, the fluctuation of mutual information is getting smaller as time passes. Finally, in Figure 9 (c) and Figure 9(f), the fluctuation of mutual information is little and its value is small. As a result, the tidal difference between Kushimoto and Uragami could be classified into these typical patterns. Therefore, the mutual information is a good analyzing method to classify the tidal motion. These features in fluctuation of mutual information have never discussed in other researches about tidal motion.

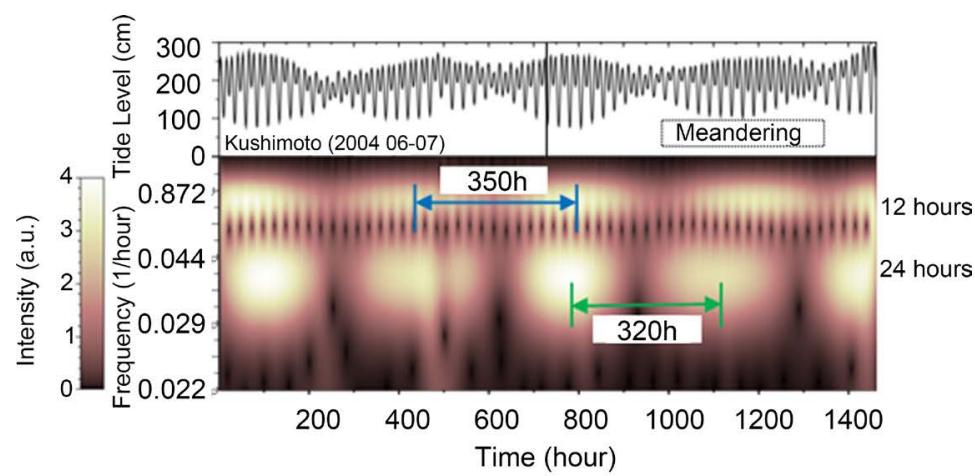

(a)

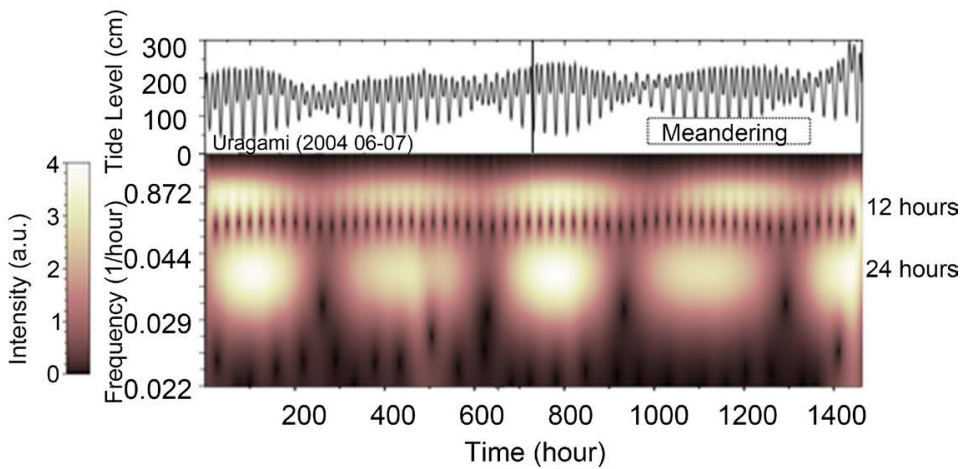

(b)

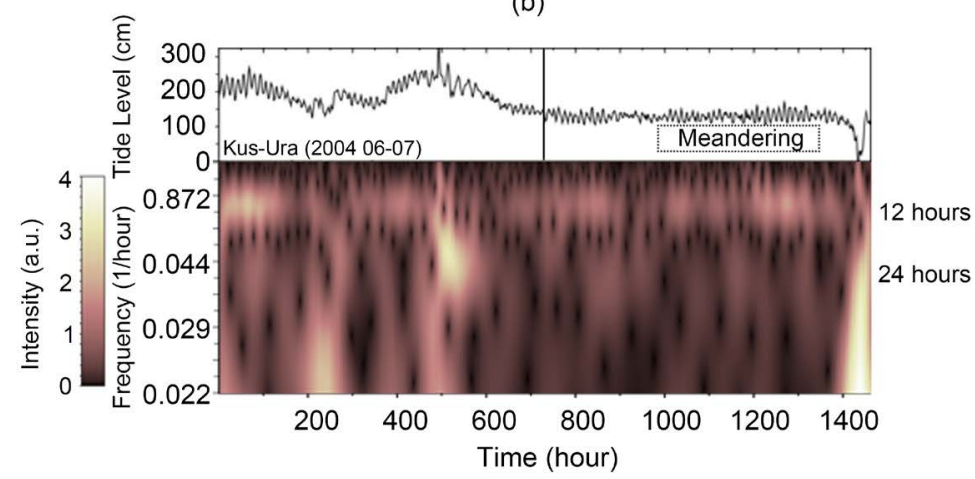

(c)

Figure 5. Tidal data observed at Kushimoto and Uragami and their wavelet analysis. 12 hours component of Kushimoto and Uragami has a swing period of 350 hours in (a) and (b). 24 hours component has a swing period 320 hours. These swing periods aren't observed in the tidal difference data of (c). (a) Tidal data and wavelet analysis on Kushimoto. (b) Tidal data and wavelet analysis on Uragami. (c) Difference of tide level and wavelet analysis. 

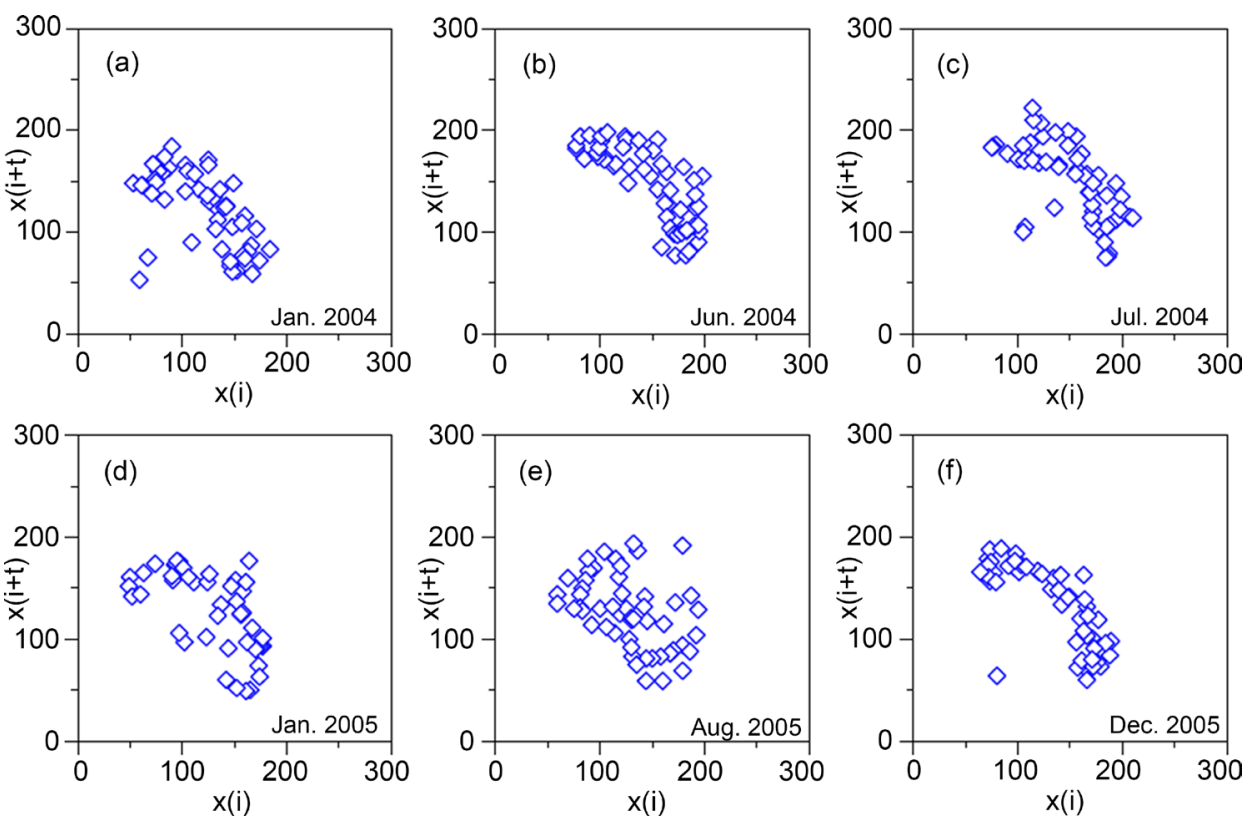

Figure 6. Lorenz's plots of tide level at Kushimoto. (a) Straight path; (b) Beginning of meandering; (c) Unstable meandering; (d) Stable meandering; (e) Ending of meandering; and (f) Straight path. The Kuroshio's flow path doesn't have an effect on Lorenz's plots of Kushimoto.
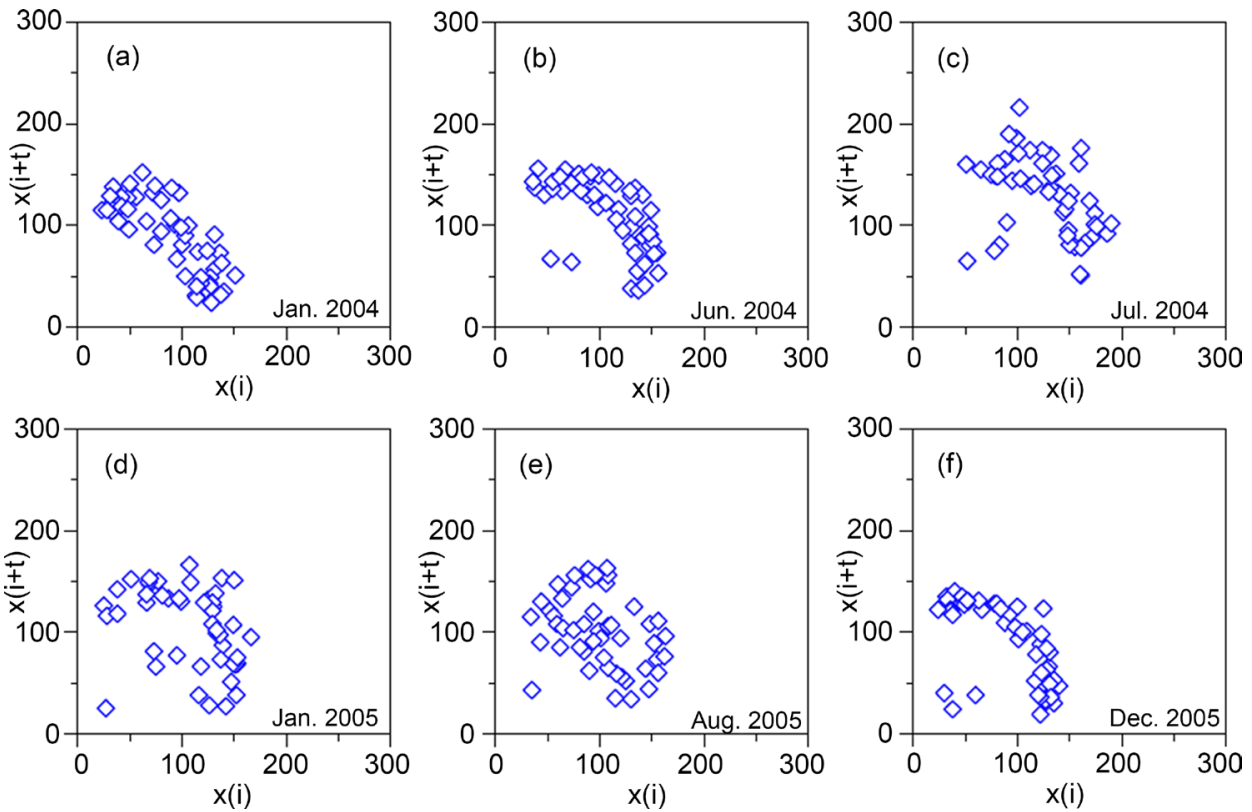

Figure 7. Lorenz's plots of tide level at Uragami. (a) Straight path; (b) Beginning of meandering; (c) Unstable meandering; (d) Stable meandering; (e) Ending of meandering; and (f) Straight path. The Kuroshio's flow path doesn't have an effect on Lorenz's plots of Uragami.

\subsection{Classification of Tidal Motion}

The tidal difference has a component of 12 hours as shown in Figure 4. Figure 10(a) shows a sinusoidal wave of 720 points during 30 days long. Figure 10(b) shows the mutual information of sinusoidal wave. Figure 10(b) has large peaks of each 12 hours 

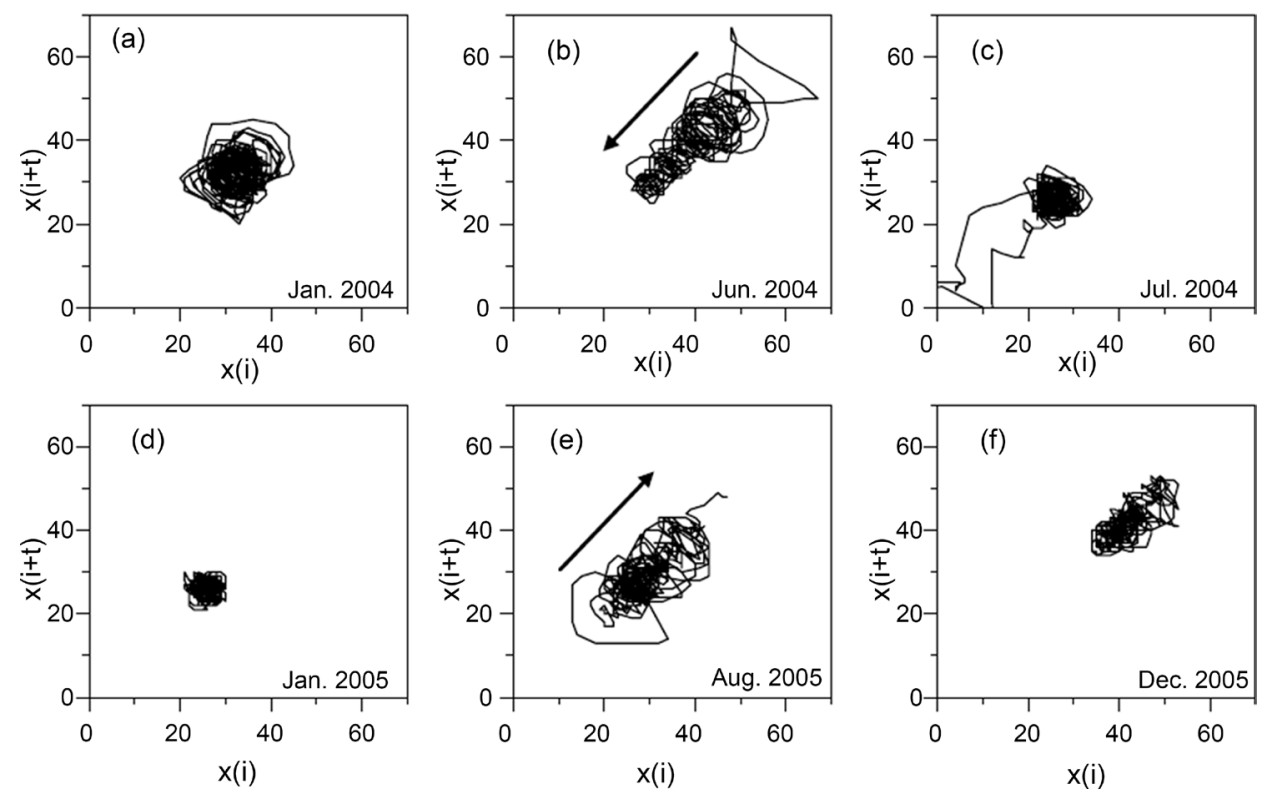

Figure 8. Phase trajectories of tidal difference data. (a) Straight path; (b) Beginning of meandering; (c) Unstable meandering; (d) Stable meandering; (e) Ending of meandering; and (f) Straight path. When the Kuroshio changes its flow from straight path to meandering path, the trajectory is stretched like (b). While Kuroshio flow is stable, the trajectory forms a round shape as shown (d).
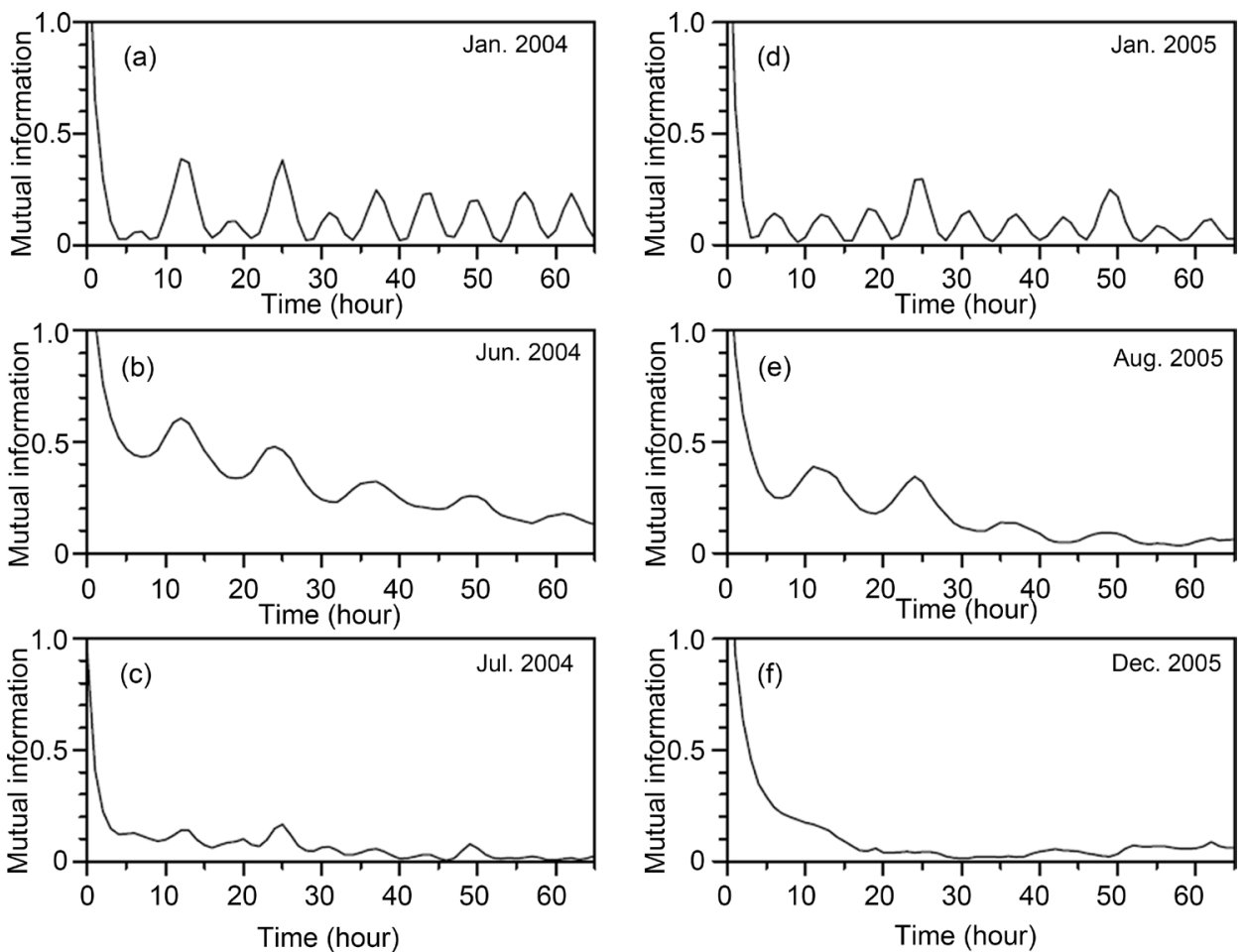

Figure 9. Mutual information of tidal difference data. (a) Straight path; (b) Beginning of meandering; (c) Unstable meandering; (d) Stable meandering; (e) Ending of meandering; and (f) Straight path. Time development of mutual information is classified into three typical patterns, (a) (d), (b) (e) and (c) (f). 


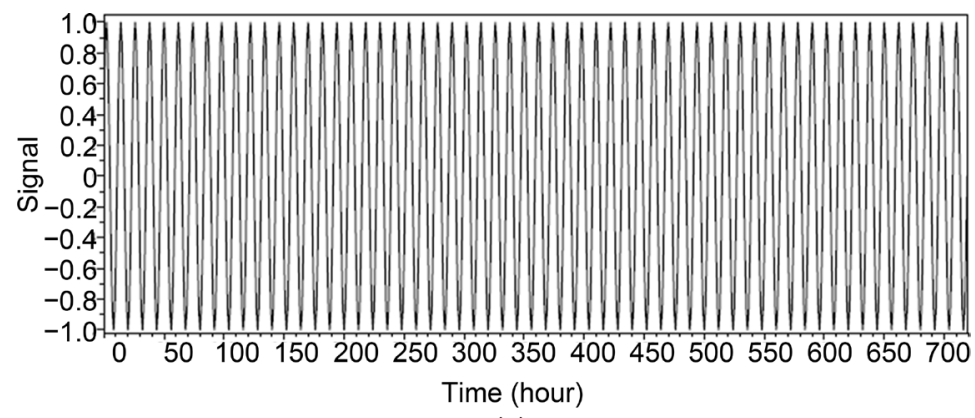

(a)

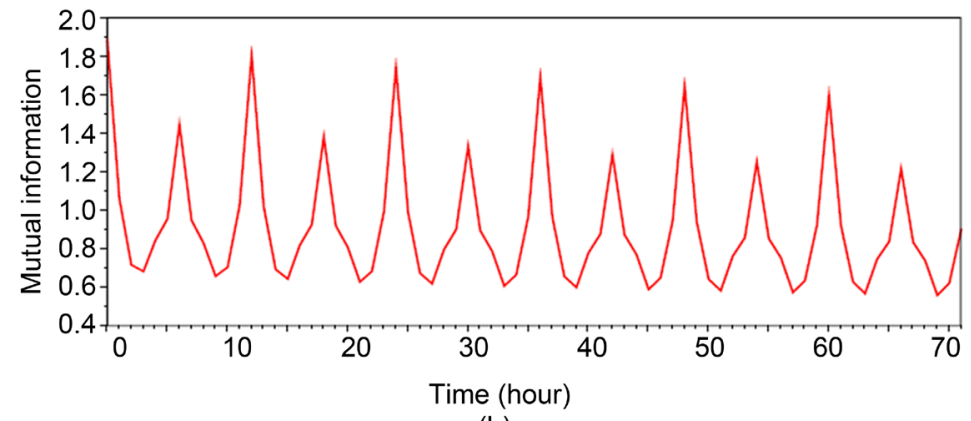

(b)

Figure 10. Periodic signal and the time development of mutual information. Sinusoidal wave makes periodic peaks of mutual information and sub peaks between them. (a) Sinusoidal signal; (b) Mutual information of sinusoidal signal.

and has sub peaks between them. This feature looks like one of Figure 9(a) and Figure 9(d). Figure 11 shows pseudo-random signal and its mutual information. As each random signal point is independent and irregular, the mutual information decreases within an hour. This feature is seen in Figure 9(c) and Figure 9(f). Therefore, the mutual information shows the character of tidal motion.

Figure 12 shows a classification model on tidal motion affected by Kuroshio Current. The tidal motion when Kuroshio flows in a straight path is located on the left side in Figure 12. On the other hand, the tidal motion when Kuroshio flows in a meandering path is located on the right side in Figure 12. The classification of tidal motion on January in 2004 when Kuroshio flows in a straight path is located at the upper left side in Figure 12, and it has a periodicity and steadiness from features of mutual information shown in Figure 12(a). The beginning of meandering is located at the center in Figure 12. The unstable meandering is illustrated at the lower right side in Figure 12 and it has a character of randomness and irregularity. In the same way, all data shown in Figures 9(a)-(f) are illustrated into Figure 12 by the methods using nonlinear analysis such as mutual information. As a result, the classification of tidal motion draws two circular orbits connected at a saddle point in Figure 12. In this paper, it is found that a new finding that relates to Kuroshio path and the tidal motion give us more interesting information of Kuroshio.

\section{Conclusion}

Tidal data observed from 2004 to 2005 at Kushimoto and Uragami were analyzed by 


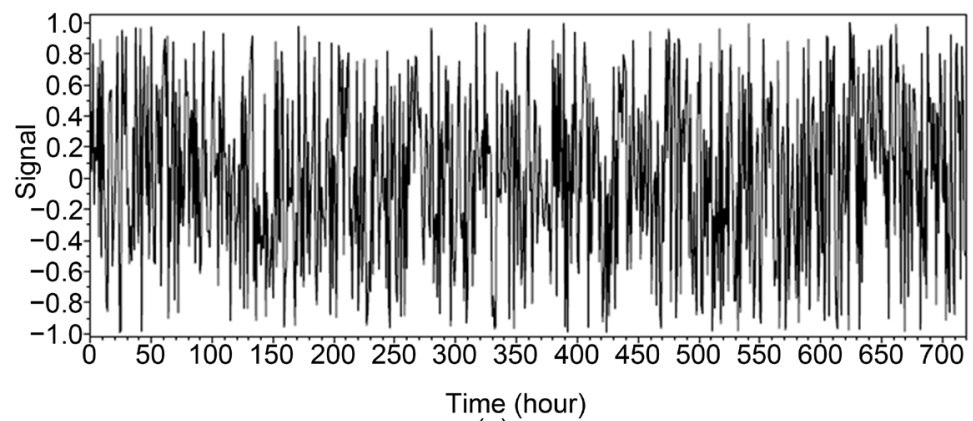

(a)

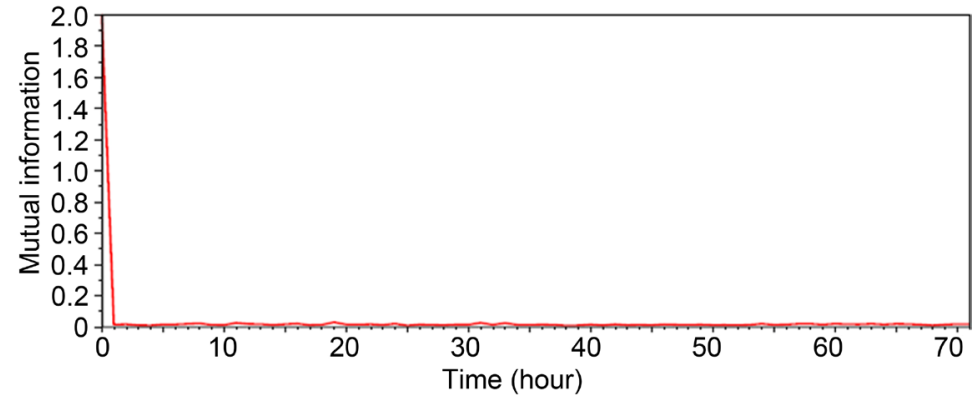

(b)

Figure 11. Random signal and the time development of mutual information. The mutual information of random signal decreases the value within an hour. (a) Pseudo-random signal; (b) $\mathrm{Mu}$ tual information of random signal.

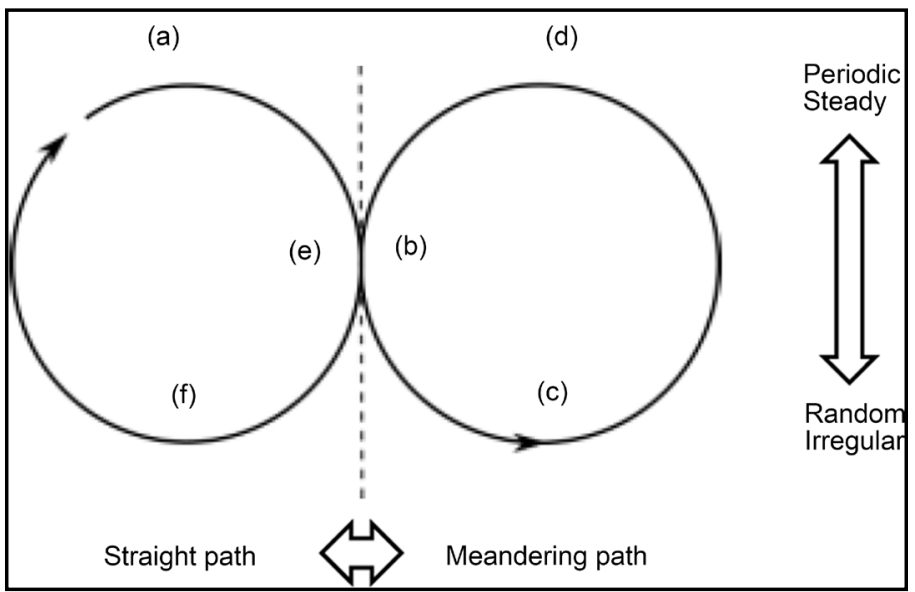

Figure 12. Schematic illustration on classification model of tidal motion. (a) Straight path; (b) Beginning of meandering; (c) Unstable meandering; (d) Stable meandering; (e) Ending of meandering; and ( $f$ ) Straight path. The classification of tidal motion draws two circular orbits connected at a saddle point between the side of straight path and the side of meandering path.

time-frequency methods and nonlinear methods. On time-frequency analysis, 12 hours component and 24 hours component swing during the period of 350 hours and 320 hours respectively. However, any remarkable differences or changes between straight path and meandering path of Kuroshio weren't seen on the result of time-frequency analysis. On the tidal difference data between Kushimoto and Uragami, the power spectrum has $1 / \mathrm{f}$ spectrum and a component of 12 hours period. Nonlinear analysis re- 
vealed a periodical structure of tidal difference that is seen in a fluctuation of mutual information while Kuroshio flow is stable. The mutual information while Kuroshio flow is unstable shows a character of randomness and irregularity of tidal motion. However, these results show that there is a stable period and unstable period regardless of the path of Kuroshio. In this research, not only bias effect of tidal motion shown by moving average of the tidal difference data but the tidal motion of a regularity and periodicity and also that of an irregularity and randomness were reviled by time-frequency methods and nonlinear methods.

\section{References}

[1] Ken, S. and Nobuhiko, H. (1998) Variability of the Path of the Kuroshio Ocean Current over the Past 25,000 Years. Nature, 392, 592-595. http://dx.doi.org/10.1038/33391

[2] Winslow and Lee, J.R. (1955) A Study of Japanese Life and Customs as Portrayed in Selected Juvenile Fiction Published from 1912 to 1954. ETD Collection for AUC Robert W. Woodruff Library, Paper 382. http://digitalcommons.auctr.edu/dissertations/382

[3] National Imagery and Mapping Agency, Bethesda (1995) Ocean Current. The American Practical Navigation, 31, 433-440. http://msi.nga.mil/MSISiteContent/StaticFiles/NAV_PUBS/APN/Chapt-32.pdf

[4] Shigeo, M. (1961) On the Difference in the Monthly Sea Level between Kushimoto and Uragami, Japan. Journal of the Oceanographical Society of Japan, 17, 197-200. https://www.jstage.jst.go.jp/article/kaiyou1942/17/4/17_4_197/_article

[5] Masaki, K. (1995) Variations of Current Path, Velocity, and Volume Transport of the Kuroshio in Relation with the Large Meander. Journal of Physical Oceanography, 25, 31033117. http://dx.doi.org/10.1175/1520-0485(1995)025<3103:VOCPVA >2.0.CO;2

[6] Yoshihiko, S. and Kohichi, F. (1999) Why Does the Sea Level Difference between Kushimoto and Uragami Show Periods of Large Meander and Non-Large Meander Paths of the Kuroshio South of Japan? Journal of Oceanography, 55, 43-51.

http://dx.doi.org/10.1023/A:1007857005988

[7] Yoichi, M., Toru, N., Keiko, N., Takashi, K., Junichi, T. and Yutaka, N. (2012) Oceanic Structure in the Vicinity of Cape Shionomisaki and Distribution of Sea Level Height. Oceanography in Japan, 20, 167-177. (In Japanese) http://ci.nii.ac.jp/els/110008799382.pdf?id=ART0009848189\&type=pdf\&lang=jp\&host=cini i\&order_no=\&ppv_type $=0$ \&lang_sw $=\& n o=1472961450 \& \mathrm{cp}=$

[8] Toru, N., Yochi, M., Keiko, N., Takashi, K., Junichi, T. and Yutaka, N. (2012) Seasonal Variation of the Sea Level Difference between Kushimoto and Uragami Tide-Gauge Stations. La Mer, 50, 77-84. (In Japanese) http://www.sfjo-lamer.org/la_mer/50-3_4/50-3-4-3.pdf

[9] J-DOSS; JODC Data On-Line Service System Provided by the Japan Oceanographic Data Center (JODC). http://www.jodc.go.jp/service.htm

[10] Masaki, K. (1980) Sea Level Variations Along the South Coast of Japan and the Large Meander in the Kuroshio. Journal of the Oceanographical Society of Japan, 36, 97-104. http://dx.doi.org/10.1007/BF02312095

[11] Masaki, K. (1987) Spectral Properties of Sea Level and Time Scales of Kuroshio Path Variations. Journal of the Oceanographical Society of Japan, 43, 111-123. http://dx.doi.org/10.1007/BF02111887

[12] Frison, T.W., Abarbanel, H.D., Earle, M.D., Schultz, J.R. and Scherer, W.D. (1999) Chaos 
and Predictability in Ocean Water Levels. Journal of Geophysical Research: Oceans, 104, 7935-7951. http://dx.doi.org/10.1029/1998JC900104

[13] Kenta, K., Satoki, S., Kenji, N. and Sumitoshi, O. (2002) Phenomenological Approaches to Co-Oscillating Tide in Ariake Bay by Time-Frequency, Nonlinear Methods. In SICE 2002. Proceedings of the 41 st SICE Annual Conference, 2, 1059-1061.

[14] Kenta, K. and Sumitoshi, O. (2002) Effects on Tidal Fluctuations by Windings of Kuroshio Current and Flow Path Monitoring by Nonlinear Analysis. In SICE 2002. Proceedings of the 41 st SICE Annual Conference, 2, 1062-1066.

[15] Fraser, A.M. and Swinney, H.L. (1986) Independent Coordinates for Strange Attractors from Mutual Information. Physical Review A, 33, 1134-1140.

http://dx.doi.org/10.1103/PhysRevA.33.1134

[16] Lin, T.J., Juang, R.C., Chen, Y.C. and Chen, C.C. (2001) Predictions of Flow Transitions in a Bubble Column by Chaotic Time Series Analysis of Pressure Fluctuation Signals. Chemical Engineering Science, 56, 1057-1065. http://dx.doi.org/10.1016/S0009-2509(00)00322-5

Submit or recommend next manuscript to SCIRP and we will provide best service for you:

Accepting pre-submission inquiries through Email, Facebook, LinkedIn, Twitter, etc. A wide selection of journals (inclusive of 9 subjects, more than 200 journals)

Providing 24-hour high-quality service

User-friendly online submission system

Fair and swift peer-review system

Efficient typesetting and proofreading procedure

Display of the result of downloads and visits, as well as the number of cited articles Maximum dissemination of your research work

Submit your manuscript at: http://papersubmission.scirp.org/

Or contact ijmnta@scirp.org 